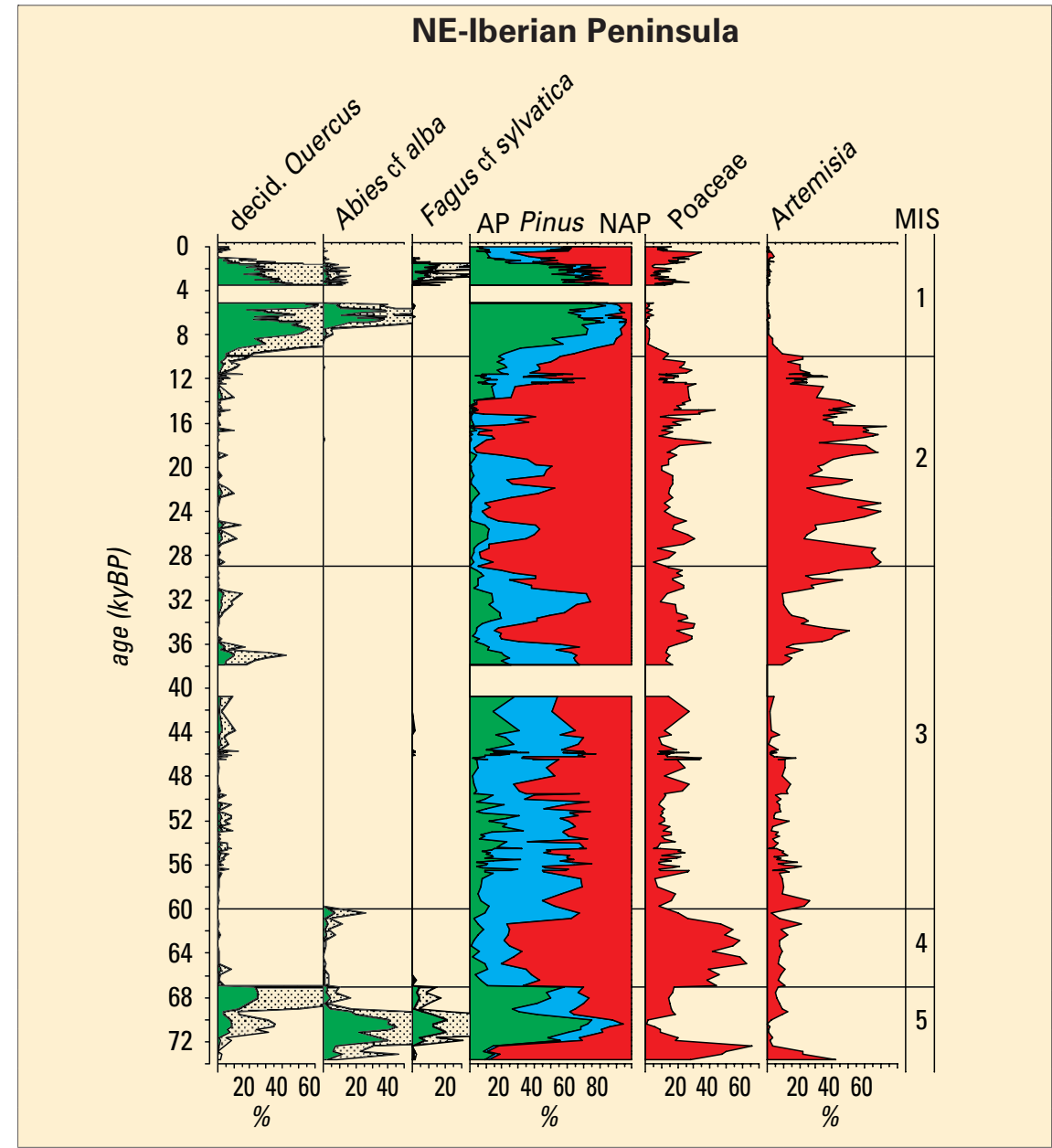

Fig. 1: The composite palynological profile of the Abric Romani, Lake Banyoles and Pla d'Estany records (Catalonia, northeastern Iberian Peninsula) shows major Late Quaternary climate variations (Burjachs et al. 1996), such as cooler temperatures during the last fluctuations of Marine Isotope Stage (MIS) 5, cool climate during MIS 4, rapid climate oscillations during MIS 3 (Dansgaard-Oeschger oscillations and Hengelo), cool and arid climate during MIS 2, and finally, temperate humid climate conditions during the Holocene.

climate and the hydrological cycle in the Western Mediterranean, and its influence on human societies through time.

Studies of Late Pleistocene organic-rich lacustrine deposits in the Banyoles area, on the foothills of the Pyrenees, are representative of research being carried out on Catalonia's palaeoclimate. Palaeo- temperatures were reconstructed from ostracode valve geochemistry, and vegetation history from pollen analysis over the last 40,000 years. Other continental and marine sequences record older palaeoenvironmental data, e.g. Abric Romani travertine or western Mediterranean marine cores. The composite palynological profile of Fig. 1 shows major climate changes during the last 70,000 years. At the beginning of the Holocene, the environment of the northeastern Iberian Peninsula was characterized by humid climate conditions, which became drier after $6,000 \mathrm{yr}$ BP. There is also evidence from fluvial sedimentary deposits and historical documentary data that the overall Holocene climate trend was punctuated by minor climatic episodes, such as the Little Ice Age. In spite of frequent signs of early Neolithic land-management, the first noticeable human impact on natural environments dates from the Bronze Age. Archaeological, palynological and sedimentological data all point to the fact that major landscape changes occurred during the late Middle Ages and the Industrial period.

Despite all the research being carried out, there is still a shortage of palaeoclimate records for CataIonia. Hopefully this will change in the future. The establishment of this research network is a first step towards determining research priorities on the understanding of past and present climate variability, and possible impacts on the region.

Information regarding the CataIan network of palaeoclimatology, its participating groups and workshops can be found at:

antalya.uab.es/_c_ceambientals/ Xarxes/XT_Paleoclima/index.htm To request further information, please send an email to gr.xtpaleocat@uab.es.

\title{
Paleoclimate Research within DEKLIM
}

\section{G. LohmanN ${ }^{1,2}$ aNd F. Sirocko ${ }^{3}$}

${ }^{1}$ Bremen University, Center for Marine Environmental Sciences, P.O. 330440, 28334 Bremen, Germany 2Alfred-Wegener-Institute for Polar and Marine Research, 27570 Bremerhaven, Germany; gerrit.lohmann@dkrz.de 3Johannes-Gutenberg University of Mainz, Institute for Geology, 55099 Mainz, Germany; sirocko@mail.uni-mainz.de

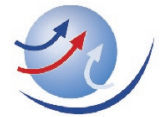

\section{DEKLIM}

Palaeo - Projects
The overarching aim of DEKLIM (German Climate Research Programme) is to improve climate predictability at global and regional scales by achieving a better understanding of long-term processes and climate modes. This includes: (i) Detailed reconstructions of the temporal and spatial structure of climate change at centennialto-millennial timescales from paleoclimatic proxy data.

(ii) Climate modeling studies to disentangle the physical and biogeochemical processes involved in the generation of these modes.

The research objective within DEKLIM-Paleo is related to the driving mechanisms of past and future climate change. Specific questions are related to the interaction of vegetation, atmospheric dynamics, 
thermohaline circulation, hydrosphere, and carbon cycle. Emphasis is placed on multiple states of the system, low-frequency climate modes, and the understanding of atmospheric and oceanic interconnections (Northern versus Southern Hemisphere forcing, ocean interconnections, relationships between low and high latitudes).

The 33 DEKLIM-Paleo projects are grouped into 13 bundles (see cover figure). Proxy data from ice cores, corals, ocean and lake sediments and tree rings are used to trace climate variations as well as extreme climatic conditions, i.e. drought and flood periods. DEKLIMPaleo is studying the patterns and causes of climate variation during the past 4 interglacials, with special attention to the transition from warm to cold intervals (e.g. the last glacial inception 116,000 years ago), the variability of the climate during the last ice age, the current warm age and particular the last 1,000 years. Model studies and data analyses complement one another. Emphasis is given to processes during the instrumental period (Corclim, TRICE, DATUN), Holocene temperature trends, variability, and forcing factors (GHOST, PROSIMUL, SALSA, MIDHOL), deglaciation (CliTrans, Oxygen Isotopes, Palaeo Isotopes), the last glacial cycle (CLIMCYC, RESPIC), and past interglacials (EEM).

Earth system models range from spatial explicit models over models of reduced complexity to conceptual models with few degrees of freedom, and are developed/applied to study climate dynamics on decadalto-multi-millennial time-scales. Forward and inverse modeling techniques are applied. In contrast to conventional time-slice experiments, the present approach is not restricted to equilibrium transitions and utilizes the available proxy data for validation.

Proxy data originate from ocean sediments, tree rings, lake sediments, corals and ice cores, i.e., archives that allow the highest resolution, in a number of cases down to annual resolution. Models are tuned until they match the observed climate history. We regard the capa-

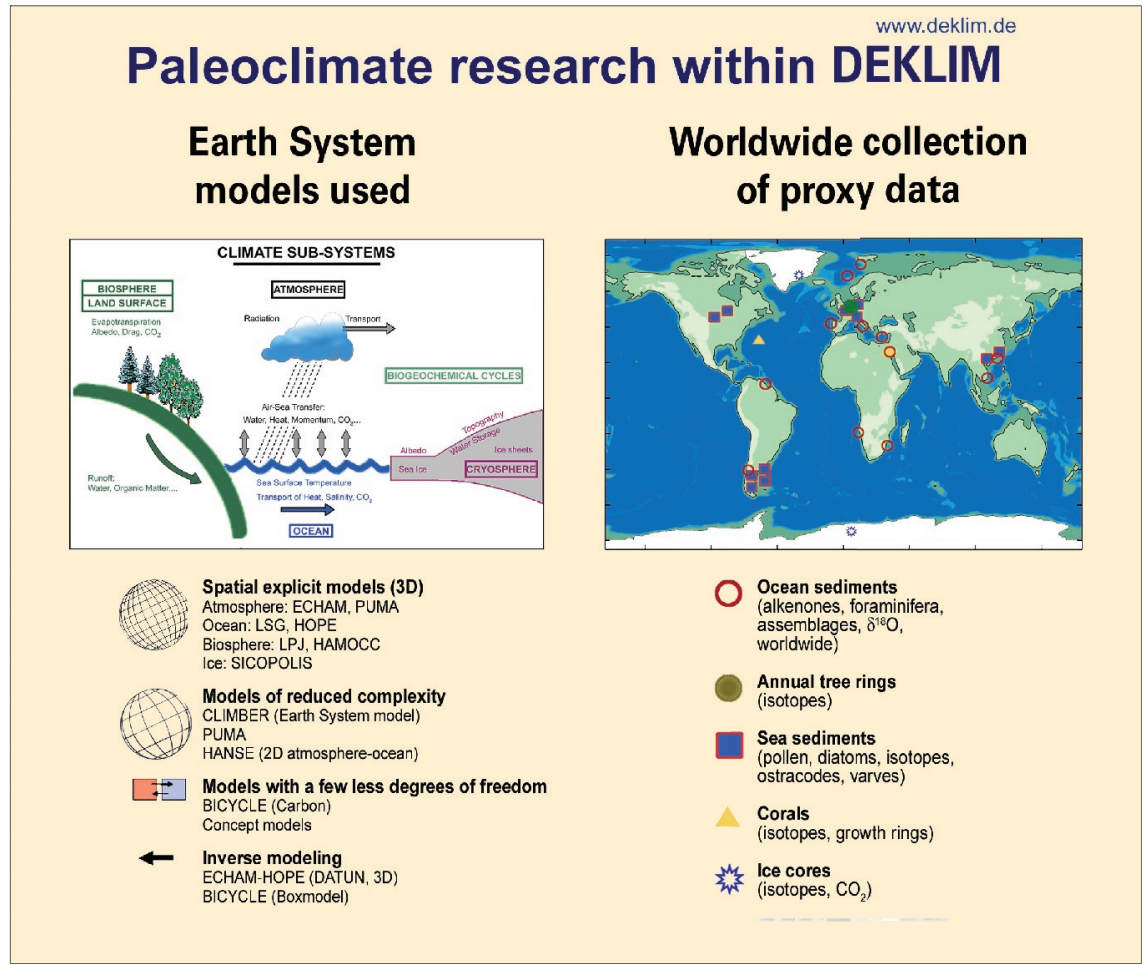

Fig. 1: Organization within DEKLIM-Paleo: Modeling approaches, proxy data used and location of data collection.

bility to reproduce the climate of the past as a first prerequisite to successfully predicting the climate of the future. If models reproduce the past with the right timing and realistic speed of processes, not only for the last 1,000 years but also on long geological time scales, they should be capable of predicting future climate change under next century insolation and greenhouse gas conditions.

DEKLIM-Paleo data are obtained worldwide (Fig. 1, right) with focus on the North Atlantic realm, southern South America, Antarctica, and South China. The data-model intercomparison improves our understanding of the climate system, allows for the identification of distinct temporal-spatial modes of climate variability for the pre-instrumental period and yields an estimation of the modeled uncertainty for climate predictions. Integrating climate histories in instrumental, model and proxy data will enable us to detect changes in the major modes of climate and their interconnections.

The close collaboration of climate reconstructing and modeling groups within DEKLIM-Paleo will foster the identification of the areas most sensitive to low-frequency climate variability and, therefore, offer the potential for achieving an improved reconstruction strategy of natural climate variations, and for separating the natural climate evolution from man-made perturbations.

An international DEKLIM/PAGES conference is scheduled for 7-10 March 2005 in Mainz under the title "The climate of the next millennia in the perspective of abrupt climate change during the late Pleistocene", see: www.uni-mainz.de/FB/Geo/ Geologie/sedi/index.html.

\section{DEKLIM Facts}

Start of funding: 2001, duration up to 5 years.

More than 100 individual projects merged into 37 joint projects.

Four major research areas:

- Paleoclimate Research (this newsletter)

- Regional Process Studies in the Baltic Sea Area

- Climate Variability and Predictability

- Climate Impact Research

Financial volume: EUR 40 million.

Young scientists' programme.

Information on all DEKLIM Projects: www.deklim.de 